\title{
A comparison of glacier melt on debris-covered glaciers in the northern and southern Caucasus
}

\author{
A. Lambrecht ${ }^{1}$, C. Mayer ${ }^{2}$, W. Hagg ${ }^{3}$, V. Popovnin ${ }^{4}$, A. Rezepkin ${ }^{4}$, N. Lomidze ${ }^{5}$, and D. Svanadze \\ ${ }^{1}$ Institute of Meteorology and Geophysics, University of Innsbruck, Innrain 52, 6020 Innsbruck, Austria \\ ${ }^{2}$ Commission for Geodesy and Glaciology, Bavarian Academy of Sciences and Humanities, \\ Alfons Goppel Str. 16, 80539 Munich, Germany \\ ${ }^{3}$ Geography Department, Ludwig-Maximilians-University, Luisenstr. 37, 80333 Munich, Germany \\ ${ }^{4}$ Department of Cryolithology and Glaciology, Geographical Faculty, Moscow State University, \\ Leninskiye Gory, 119992-Moscow, Russia \\ ${ }^{5}$ Vakhushti Bagrationi State Institute of Geography, Tbilisi, Georgia
}

Received: 14 December 2010 - Published in The Cryosphere Discuss.: 1 February 2011

Revised: 20 June 2011 - Accepted: 23 June 2011 - Published: 4 July 2011

\begin{abstract}
The glacier coverage in the Caucasus Mountains underwent considerable changes during the last decades. In some regions, the observed reduction in glacier area is comparable to those in the European Alps and the extent of supra-glacial debris increased on many glaciers. Only a few glaciers in the Caucasus are monitored on a regular basis, while for most areas no continuous field measurements are available. In this study, regional differences of the conditions for glacier melt with a special focus on debris covered glacier tongues in the well-studied Adyl-su basin on the northern slope of the Caucasus Mountains (Russia) is compared with the Zopkhito basin which has similar characteristics but is located on the southern slope in Georgia. The paper focuses on the effect of supra-glacial debris cover on glacier summer melt. There are systematic differences in the distribution and increase of the debris cover on the glaciers of the two basins. In the Adyl-su basin an extensive debris cover on the glacier tongues is common, however, only those glacier tongues that are positioned at the lowest elevations in the Zopkhito basin show a considerable extent of supra-glacial debris. The observed increase in debris cover is considerably stronger in the north. Field experiments show that thermal resistance of the debris cover in both basins is somewhat higher than in other glaciated regions of the world, but there is also a significant difference between the two regions. A simple ablation model accounting for the effect of debris cover on ice melt shows that melt rates are considerably higher in the northern basin despite a wider debris distribution. This difference between
\end{abstract}

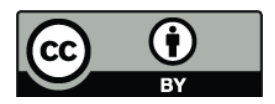

Correspondence to: A. Lambrecht (astrid.lambrecht@uibk.ac.at) the two regions can be attributed to different meteorological conditions which are characterised by more frequent cloud cover and precipitation in the south. Furthermore ablation is strongly influenced by the occurrence of supra-glacial debris cover in both basins, reducing the total amount of melt on the studied glaciers by about $25 \%$. This effect mitigates glacier retreat in the lower sectors of the ablation zones considerably. The sensitivity to moderate changes in the debris cover, however, is rather small which implies only gradual changes of the melt regime due to debris cover dynamics during the near future.

\section{Introduction}

Debris covered glaciers are common in many mountain regions of the world and the observed retreat of glaciers is accompanied by an increasing extent of debris cover on glacier tongues (Scherler et al., 2011). Therefore, the role of the supra-glacial debris cover control over ice melt is likely to become more significant with the increasingly negative glacier mass balances. Investigations of the impacts of supraglacial debris on ice melt date back to the 1950s (Østrem, 1959) and confirm that ice melt is enhanced by a very thin layer of supra-glacial debris while thicker debris layers reduce melt in comparison with that of the clear ice (e.g. Fuji, 1977; Mattson et al., 1993). Melt rates of the debris-covered glaciers, however, vary considerably due to different factors, for example, thermal properties of the supra-glacial debris cover (Nakawo and Young, 1981). Dedicated process studies were carried out focusing on the thermal conditions of the sub-debris ice melt (Brock et al., 2007; Mihalcea et al. 2006;

Published by Copernicus Publications on behalf of the European Geosciences Union. 
Nicholson and Benn, 2006) highlighting important differences between clear ice and sub-debris melt due to changes in individual terms of the energy balance. While net radiation is the main energy source for ice melt on debris-free glaciers, latent heat flux and conduction through the supra-glacial material determine the sub-debris melt rates (Takeuchi et al., 2000).

In addition to process studies, large scale mapping of debris cover is important for a realistic estimation of melt water production by debris covered glaciers (Taschner and Ranzi, 2002; Mihalcea et al., 2008a; Hagg et al., 2008). This is best achieved by the use of satellite imagery (Paul et al., 2004; Stokes et al., 2007) and an important aim of a number of studies was the determination of supra-glacial debris thickness using remote sensing information (Mihalcea et al., 2008b; Foster, 2010). Several studies attempted to include debris cover into glacier melt parameterisations with a different degree of sophistication (e.g. Kayashta et al., 2000; Konovalov, 2000; Reid et al., 2010). Here we attempt to integrate field measurements, the analysis of remote sensing imagery and a simple ablation model for evaluating the role of the debris cover on the ice melt for two small basins in the Caucasus Mountains, located north and south of the main divide, where at least some glaciological and meteorological information is available for longer periods.

\section{The Caucasus region}

The Caucasus mountain range extends from the Black Sea to the Caspian Sea in a West-East direction with glaciers covering an area of about $1600 \mathrm{~km}^{2}$ (Stokes et al., 2006). The range creates a meteorological boundary between northern and southern slopes and, in general, larger glaciers are found in the north. The west-east climatic gradients are prominent especially on the southern slope, whereby the western sector is characterized by more humid conditions with annual precipitation reaching $3000 \mathrm{~mm}$, while the east is semiarid receiving as little as $200 \mathrm{~mm} \mathrm{yr}^{-1}$ (Volodicheva, 2002). As a result, water availability varies across the region. The Caucasus Mountains are the main source of runoff for the densely populated planes and snow and ice melt is crucial for water production in many parts of the region. A general glacier retreat is observed in the Caucasus and between 1985 and 2000, glaciers of the region lost $10 \%$ of their surface area with more than $90 \%$ of the glaciers retreating (Stokes et al. (2006).

Glacier melt in the Caucasus occurs mainly between June and August (JJA) (Shahgedanova et al., 2009a). The JJA mean temperatures were increasing at several weather stations in the Caucasus during the last 40 years at a rate of $0.05^{\circ} \mathrm{C}$ per year (Shahgedanova et al., 2009b). The last two decades have been the warmest during almost 80 years of observations and variations in precipitation do not compensate for enhanced ice melt in this period (Shahgedanova et

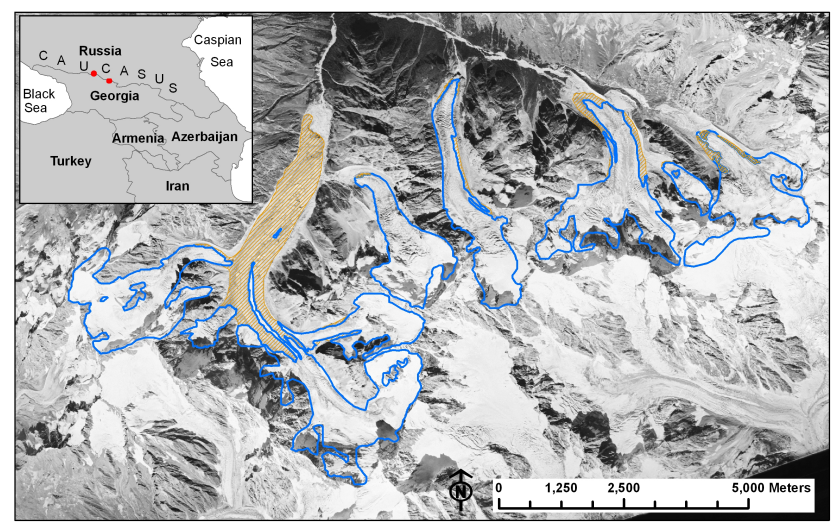

Fig. 1. CORONA image of the Adyl-su Valley from September 1971 with the boundaries of the selected glaciers (the Djankuat Glacier is at the far right) and the supra-glacial debris cover extent (orange).

al., 2009a). Furthermore model studies indicate that for the most likely groups of scenarios (A2 and B2) the air temperature will further increase, especially during the summer months (May-August, Shahgedanova et al., 2009a). Therefore glacier melt is expected to increase in the Caucasus (Stokes et al., 2006) and has already increased according to a negative trend of the annual mass balance of Djankuat glacier during the 30-year period from 1979 to 2009.

Although climatic conditions are different north and south of the Main Caucasus Ridge, the observed differences in glacier change in both regions have not been compared in detail due to the lack of ground based observations. After the end of the Soviet Union most glaciological observation programs have been dismissed, especially in the new, independent countries. The initiation of new monitoring sites is laborious and difficult.

\section{Study sites}

Our test regions for this comparative study are situated in the Greater Caucasus on both sides of the main divide, at a distance of only $64 \mathrm{~km}$ from each other. In both regions the drainage basin of a small river has been chosen for the investigations, allowing us to directly compare the relevance of the glaciers to the discharge conditions in the respective basin. Also this approach provides the opportunity to use the results for future run-off investigations.

On the northern side, in the upper Baksan valley, 6 glaciers in the Adyl-su (tributary to the Baksan) valley have been selected for closer investigation (Fig. 1). Glaciological observations in this region date back to 1967 , with the Djankuat Glacier being one of the benchmark glaciers for the World Glacier Monitoring service (Popovnin, 1999; WGMS, 2009). The total glaciated area in this valley was $21.4 \mathrm{~km}^{2}$ in 2003 and the glacier tongues reach down to about $2350 \mathrm{~m}$. The 


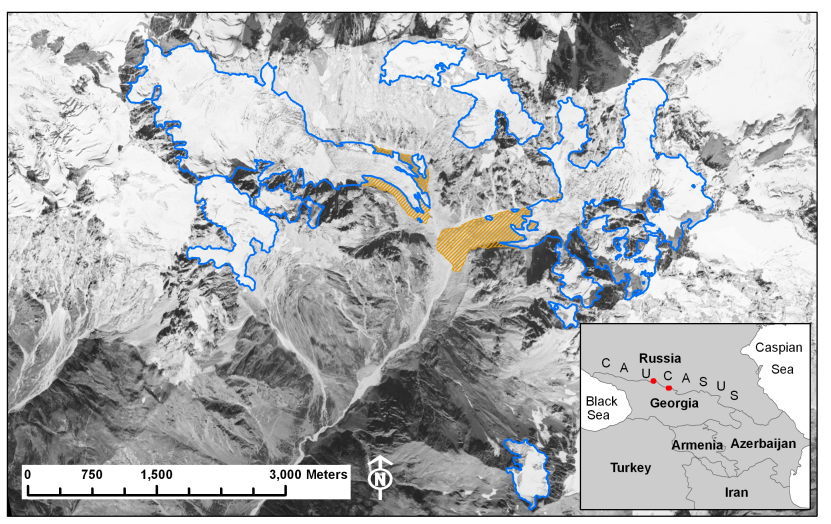

Fig. 2. CORONA image from September 1971 for the Zopkhito basin with the boundaries of all glaciers and the supra-glacial debris cover of the Zopkhito and Laboda Glaciers (orange).

lowest parts of all these glaciers are debris covered. In order to allow future comparisons with area precipitation and discharge, the basin was restricted to the Adyl-su valley down to the junction with the Baksan river (total area: $100.24 \mathrm{~km}^{2}$ ),

In the southern Caucasus, glaciers located in the Zopkhito valley, a part of the upper Rioni drainage basin (Fig. 2), were selected for investigation. Nine glaciers (with a total area of $7.9 \mathrm{~km}^{2}$ in 2006) are situated in this part of the basin (total area: $49.35 \mathrm{~km}^{2}$ ), which correspond to a relative glacier cover of $16 \%$. Only two of them, the Zopkhito Glacier and the Laboda Glacier, are partly debris-covered. These two glaciers are the only ones in the region with low reaching tongues (about $2475 \mathrm{~m}$ ), where supra-glacial debris can accumulate. The other glaciers are debris-free cirque glaciers at higher elevations. Due to the much steeper relief south of the divide the potential areas which could be occupied by glaciers are restricted and in general glaciation is much smaller on the southern slope (Dolgushin and Osipova, 1989).

Ablation underneath supra-glacial debris is very dependent on the local conditions and thus field measurements are required at least on some glaciers which are representative for the studied region. The field work conducted between 2007 and 2009 focused on the melt conditions of two partly debris-covered glaciers, namely the Djankuat Glacier (Russia) in the north and the Zopkhito Glacier (Georgia) in the south. Apart from different aspects (NW and SE, respectively), the mean elevations of the debris-covered glacier tongues are comparable, with the Djankuat Glacier tongue located about $100 \mathrm{~m}$ higher than the tongue of the Zopkhito Glacier. On both glaciers debris covers about $10 \%$ of the glacier area being concentrated in the lower part of the ablation zone.

In order to study sub-debris ice melt also information on the debris composition is required. In general the petrography of the Caucasus is relatively uniform, with the axial part composed by Jurassic igneous and metamorphic rocks (gran- ites and gneisseous granites). The local petrography, however, is much more diverse. In the Adyl-su basin, granitoides prevail and the glaciers are situated in the upper reaches of rift structures parallel to the main axis of the Greater Caucasus. The southern test area is tectonically different, being represented by upthrust and overthrust structures, with rock units in the north-south direction. Here the petrographical composition is more complex with a combination of volcanogenic origin (andesites, dolerites, pillow lavas) and flyschoid strata (finely-dispersed argillo-arenaceous and marl deposits). Both pertographical units (volcanogenic and flyschoid) are less resistant to erosion and denudation than granitoids. Together with the tectonic differences, this results in more favourable conditions of debris accumulation on glaciers in the Southern test area (Zopkhito) than in the Northern one (Adyl-su) (Geologia SSR, 1964 and 1968).

\section{Data collection}

\subsection{Glacier and debris cover mapping}

Apart from the actual ablation conditions, it is also necessary to evaluate the evolution of the selected glaciers during the recent past, in order to allow conclusions about past and future glacier trends in the region. In the Caucasus, as in many other glacier covered regions, debris cover is an important control for ice ablation (Mayer et al., 2010, Hagg et al., 2008) and thus the temporal changes of debris cover need also to be taken into account.

The glacier change investigations are based on a set of remote sensing images, which are used to delineate boundaries of the main glaciers within the two basins and the extent of debris cover for different years. By combining glacier maps with a digital elevation model, the area-elevation distribution of the glacier cover and the aspect of the glacier tongues have been determined. Combined use of these data makes it possible to characterise changes in glacier area and proportion of glacier area covered by debris during the last $30-40$ years in the selected regions.

For the Djankuat basin the information about glacier boundaries is available for 1985 and 2000 (Stokes et al., 2007). Information about the extent of debris cover is available for six years from in situ mapping between 1968 and 1999 (Popovnin and Rozova, 2002). In order to update this information, a Spot Image from 30 August 2006 (with a spatial resolution of $10 \mathrm{~m}$ ) was used as a reference image for all remote sensing investigations including the glacier boundary delineation. The image was orthorectified using the SRTM $90 \mathrm{~m}$ digital elevation model (Rabus et al., 2003; a product of the National Aeronautics and Space Administration (NASA)). CORONA imagery dating from 20 September 1971 with a resolution of $5 \mathrm{~m}$ was co-registered onto the Spot image, but the original spatial resolution was kept to obtain the highest possible accuracy for the glacier extent and debris cover distribution in 1971. 
In case of the Zopkhito basin a SPOT image from 8 June 2008 and Corona imagery from 20 September 1971 are the basis of the analysis. Additional information was used for 2006 based on a high resolution Digital Globe image (Google Earth) and for 2008 from Landsat ETM+, in order to obtain cloud free conditions for the entire glacier cover. The glacier boundaries and the debris cover were mapped manually on all images in order to obtain results of similar quality for all of the different image sources. The classification of debris cover on remote sensing imagery is not straightforward. Our approach was to map clean ice surfaces first. It is usually impossible to resolve sub-pixel clean ice patches in otherwise debris covered areas and vice versa. The next step will be to manually map glacier margins, which in most cases is possible by analyzing changes in slope, general surface roughness and obvious break lines on the images. With this approach, very dark ice and thin dust films on clean ice might be included in the debris cover class. An additional visual quality check will improve the results, but it does not guarantee a unique and correct solution. According to our observations in the field, the transition between clean ice and a clearly identifiable debris cover is usually not very large on the sampled glaciers and wrong classifications will be of an order of a few pixels. The results were also compared with debris cover maps which exist for Djankuat glacier (Popovnin and Rozova, 2002) and newer mapping results. Stokes et al. (2007) used a similar approach and achieved satisfactory results for the Djankuat glacier.

In addition, spatial distribution of the debris cover on the glacier tongue was mapped in detail in the field. This map was used to quantify the sub-debris melt rates on a spatially distributed basis and to validate the results from remote sensing analysis.

\subsection{Ablation measurements}

The field observations were carried out between 2007 and 2008 on Djankuat and between 2008 and 2009 on Zopkhito glaciers concentrating on the ice ablation on the glacier tongues and the mapping of supra-glacial debris cover. For the detailed observations of recent ablation conditions, networks of 11 stakes each were installed in addition to the standard mass balance stake network on the Djankuat Glacier in June 2007 (Fig. 3) and in the ablation area of the Zopkhito Glacier in June 2008 (Fig. 4), respectively. The elevation range of the sub-debris ablation network is about $250 \mathrm{~m}$ on both glaciers. Positions of the stakes were selected to represent variations in debris cover thickness, elevation range and aspect.

Installation of the stake networks and subsequent monitoring covered a period from 26/06/2007 until 27/09/2007 at the Djankuat Glacier, while thermistor information of debris temperatures is available until 01/07/2007. On Zopkhito Glacier, the stake network was installed at the end of June 2008, however, the stakes were reinstalled at the beginning

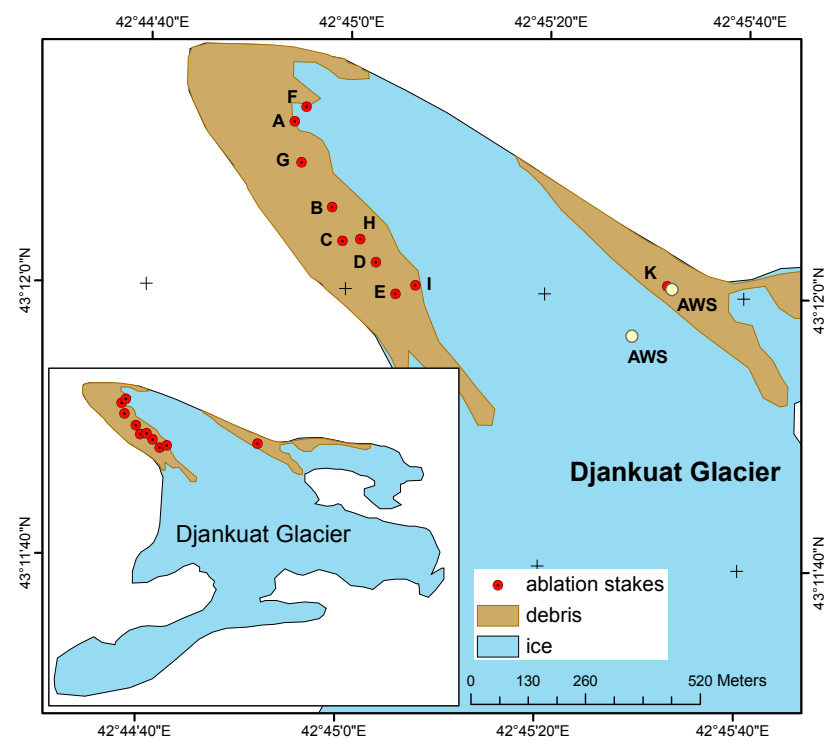

Fig. 3. Overview of Djankuat glacier including the mapped debris cover, the position of the ablation stakes and the automatic weather stations (AWS).

of July 2009 for monitoring a second ablation season. The stake height and the thickness of the debris cover were measured after the installation and subsequently the stake measurements were continued throughout the ablation season to obtain melt rates for different debris thicknesses and meteorological conditions. On both glaciers, measurements were carried out twice a day in a first period of intensive observations ( 1 week to 10 days), followed by a less frequent observation schedule. The state of the debris-covered surface was restored to its original condition after the placement of the stake and the natural temperature profile in the debris cover was already reached again after several hours, maximum one day. Stake measurements have been conducted manually by measuring the distance between the stake tip and the debris surface. The accuracy of the measurements was above $1 \mathrm{~cm}$.

At some stakes thermistors were used to monitor the temperature profile in the debris layer, in order to derive the thermal properties of the debris cover. Usually three thermistors in a vertical profile were placed in the debris cover to obtain a good resolution of the temperature gradient. In general, the temperature measurements show that for debris thicknesses of less than $40 \mathrm{~cm}$ the daily temperature cycle is fully compensated during the night. The accuracy of the thermistors used in the debris cover (Tiny Tag TGP 4020 data logger, including a $10 \mathrm{~K}$ NTC external thermistor, accuracy: $\sim 0.2^{\circ} \mathrm{C}$ ) is good enough to determine the established mean daily temperature gradient, which is in the order of $1.0^{\circ} \mathrm{C} \mathrm{cm}^{-1}$. 
Table 1. Details of the sensors used on Djankuat and Zopkhito glaciers for monitoring meteorological parameters.

\begin{tabular}{llc}
\hline Sensor & Variable & Height above the surface (m) \\
\hline $\begin{array}{l}\text { Temperature and humidity } \\
\text { HMP45C Vaisala probe }\end{array}$ & $\begin{array}{l}\text { Air temperature and relative } \\
\text { humidity }\end{array}$ & 2 \\
\hline $\begin{array}{l}\text { CS100 SETRA barometric } \\
\text { pressure sensor }\end{array}$ & Atmospheric pressure & \\
\hline A100R anemometer & Wind speed & 2.5 \\
\hline W200P-01 wind vane & Wind direction & 2.5 \\
\hline $\begin{array}{l}\text { Kipp \& Zonen CRN1 } \\
\text { net radiometer }\end{array}$ & $\begin{array}{l}\text { Incoming and reflected solar } \\
\text { radiation; long-wave terrestrial } \\
\text { and returned radiation }\end{array}$ & 1.5 \\
\hline SR50A sonic ranging sensor & Distance to the surface & Variable \\
\hline
\end{tabular}

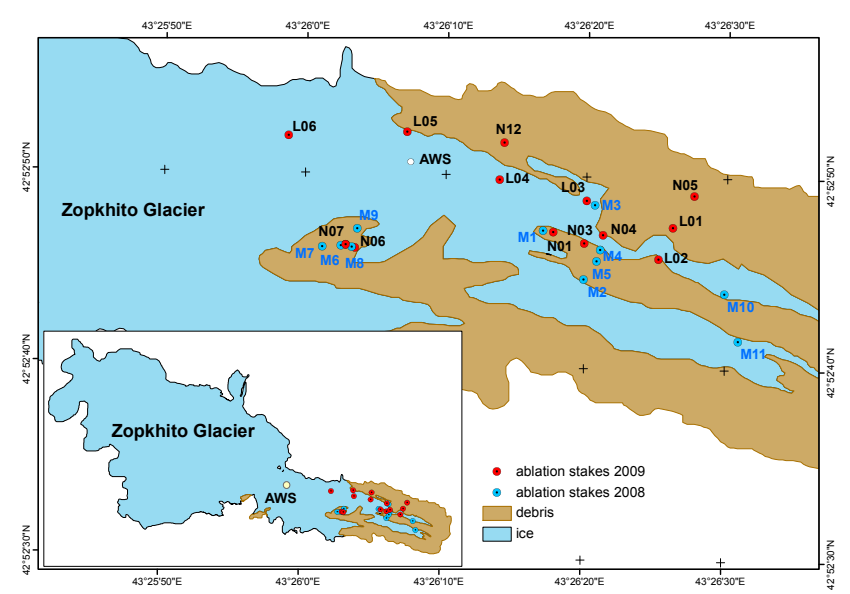

Fig. 4. Overview of Zopkhito glacier including the mapped debris cover and the position of the ablation stakes in both ablation seasons, as well as the location of the AWS.

\subsection{Meteorological Data}

Campbell Scientific automatic weather stations (AWS) were installed on both glaciers between early June and early October measuring a range of meteorological variables and distance to the surface used in the calculation of glacier melt rates.

On Djankuat Glacier, two stations were installed at about $2960 \mathrm{~m}$ a.s.l., one over the clear ice and another over the debris covered surface (Fig. 3), close to the location where temperature gradients in the debris cover were recorded by several thermistors. On Zopkhito Glacier, an AWS was installed in the upper part of the ablation zone at about $2850 \mathrm{~m}$ a.s.l., just below a steep ice fall in 2008 (Fig. 4). This station was situated on clear ice. A simpler weather station (including air temperature, humidity and wind speed sensors) was installed on a moraine ridge in the central part of the glacier tongue for the duration of the field campaign. The full-range Campbell Scientific AWS was removed in the autumn 2008 and reinstalled at a lower elevation on the glacier in spring 2009, ensuring the coverage of meteorological conditions during the following ablation season. All sensors employed at the AWSs took measurements every $5 \mathrm{~s}$ and stored information averaged over $15 \mathrm{~min}$ intervals. The details are listed in Table 1 . The AWS were visited every week to adjust their positions and maintain the correct alignment of the instruments.

Apart from the short term measurements conducted on the glaciers, longer term meteorological data are required to understand glacier response to the varying climatic conditions. In the northern Caucasus, such data were obtained from the Terskol weather station located in the main valley of the Baksan River in $20 \mathrm{~km}$ from Djankuat Glacier at the elevation of $2141 \mathrm{~m}$ a.s.l. The parallel measurements conducted at Terskol and on Djankuat using the AWS in June-October 2007 showed a reasonably high correlation for the daily air temperature (coefficient of determination $r^{2}: 0.75$ ) and a mean temperature difference of $5.9^{\circ} \mathrm{C}$. The position, surroundings and observational programme at Terskol remain unchanged since the start of observations in 1952 when measurements commenced and it is possible to use a simple lapse rate function, derived from the period of parallel measurements, to calculate air temperature at the glacier in the past. Data from the Ambrolauri weather station situated $45 \mathrm{~km}$ south-west from Zopkhito glacier at $544 \mathrm{~m}$ a.s.l. were used to characterise meteorological conditions in the southern catchment. There was a strong correlation between the AWS air temperature data from 2008-2009 and air temperature measured at Ambrolauri with a coefficient of determination of 0.74 . The mean temperature difference was $11.9^{\circ} \mathrm{C}$ and deviations from the mean temperature difference were due to the frequent local rainfall events (accompanied by a drop in temperature) at the glacier in the afternoon in the summer season when it 


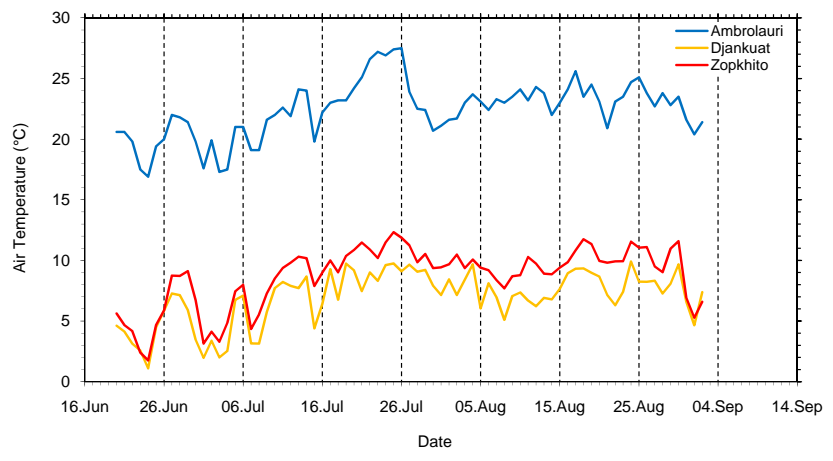

Fig. 5. Comparison of parallel daily mean air temperature measurements $\left({ }^{\circ} \mathrm{C}\right)$ in 2008 on both sides of the Main Caucasus Ridge: at Ambrolauri weather station (550 m a.s.1.) and on the Zopkhito Glacier (about $2700 \mathrm{~m}$ a.s.l.) on the southern slope and on the Djankuat Glacier (2960 m a.s.l.) on the northern slope.

was dry (and warm) at the lowland station. The observations showed that the southern site experienced higher cloudiness during summer due to the advection of humid air from the Black Sea generating the observed precipitation events. A comparison of air temperatures during the summer of 2008 (Fig. 5) shows, however, that air temperatures at both sites are rather similar if the vertical temperature gradient is accounted for. Air temperatures at Djankuat Glacier were about $0.5^{\circ} \mathrm{C}$ lower than at Zopkhito at the comparable altitudes.

\section{Analysis of glacier and debris cover evolution}

The results of the temporal evolution of the glaciers in the two basins are mainly based on the remote sensing analysis, complemented by own observations. Glaciers are located between $2300 \mathrm{~m}$ to $4300 \mathrm{~m}$ in the Adyl-su basin and cover about $21 \%$ of the area (Djankuat glacier accounts for about $3 \%$ of the basin area). The ice cover reaches its maximum extent between $2900 \mathrm{~m}$ and $3700 \mathrm{~m}$. The supra-glacial debris cover in the valley is limited to the elevations between $2350 \mathrm{~m}$ and $3200 \mathrm{~m}$ and there is no clear ice glacier surface within the lowest $150 \mathrm{~m}$ of this band (Fig. 6). Between $2500 \mathrm{~m}$ to $2800 \mathrm{~m}$, the areas of debris-covered ice and clear ice are approximately the same. At higher elevations, the supra-glacial debris cover gradually declines and disappears at about $3200 \mathrm{~m}$.

In the Zopkhito basin, the extent of the supra-glacial debris cover is more limited. Only a small proportion of the Zopkhito Glacier tongue is covered by debris. Apart from supra-glacial moraine ridges across the middle section of the tongue, the debris cover extends mainly over the lowermost part of the glacier. There, continuous and strong melting throughout the summer increases the debris cover on the glacier surface by removing ice and adding intraglacial debris. The debris cover is rather thin on the steeper parts of the tongue, where the material usually is removed by small

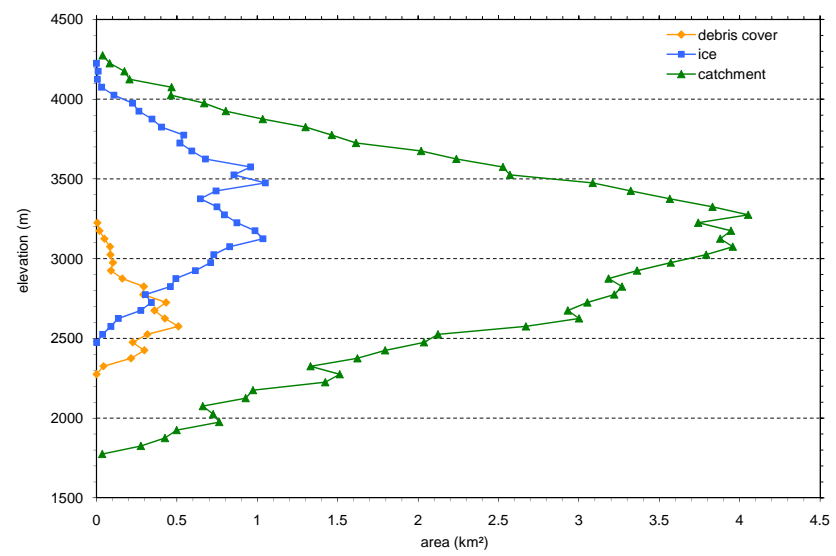

Fig. 6. Area elevation distribution for the six glaciers in the Adylsu basin in 2000 based on Stokes et al. (2006) and the STRM $90 \mathrm{~m}$ digital elevation model. The area distribution is divided into clean ice and debris covered fractions.

debris slides leaving only thin dust layers on the ice surface. In the flatter parts, the supra-glacial debris is composed of a wide variety of grain sizes, from very fine grained sand to big stones. Larger boulders, however, are few. Fig. 7 shows the area-elevation distribution of the Zopkhito and Laboda Glaciers for 2006 (based on elevations from SRTM in 2000). The other glaciers in the basin have no debris cover and are thus not included in this analysis.

The hypsographic curve of the glaciers in the south is similar to that in the Adyl-su basin, but with the lower glacier margin about $100 \mathrm{~m}$ higher than in the north. Proportion of glaciated area reaches its maximum in a similar elevation band while the relative area decrease with altitude starts at about $3400 \mathrm{~m}$, which is $200 \mathrm{~m}$ lower than in the Adyl-su basin. Only the lowermost $300 \mathrm{~m}$ of the glacier cover (from $2450 \mathrm{~m}$ to $2750 \mathrm{~m}$ ) exhibit a significant fraction of debris cover, while small debris covered areas are detected up to $3600 \mathrm{~m}$.

In comparison to the Adyl-su basin, the proportion of ice free areas in the Zopkhito basin is considerably larger in lower elevation bands. Almost $40 \%$ of the total area is downstream of the lowest glacier tongue, while in the Adyl-su basin this is only a small fraction. The elevation bands showing the largest area in the Adyl-su basin are concentrated between $3000 \mathrm{~m}$ and $3400 \mathrm{~m}$. In the Zopkhito basin, the distribution of these elevation bands stretches between $2100 \mathrm{~m}$ and $2800 \mathrm{~m}$.

A comparison of the debris extent on the available remote sensing images shows an increase of the relative debris cover over time (Fig. 8). For the glaciers in the Adyl-su basin, where imagery is available at intermediate dates, the supraglacial debris distribution remained nearly constant at about $16 \%$ between 1971 and 1991. Between 1991 and 2006, the debris covered area started to increase noticeably reaching $23 \%$ within 15 years. For the Zopkhito basin glaciers, the 


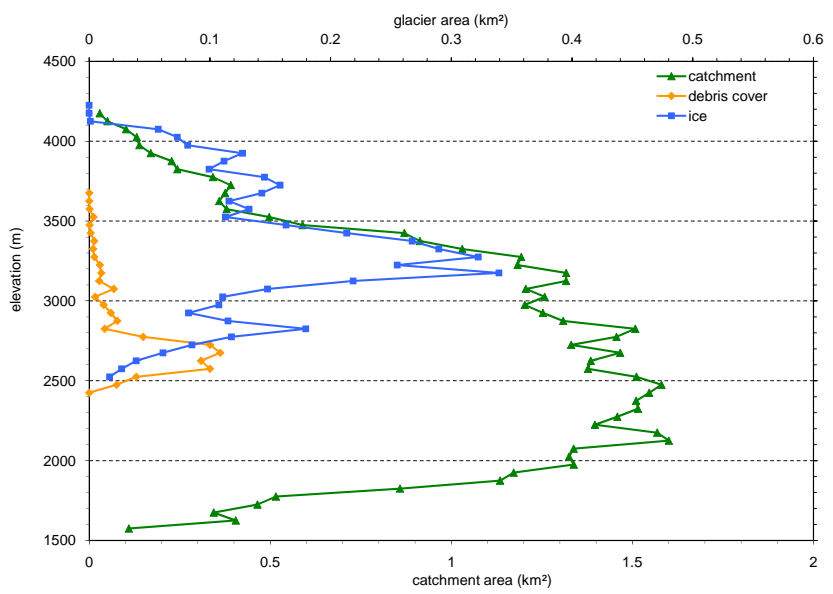

Fig. 7. Area elevation distribution for the Zopkhito and Laboda Glaciers based on the manually delineated glacier boundaries for 2006 and the STRM 90 m digital elevation model. Note the different scales for the area of the glaciers and the catchment (upper and lower $\mathrm{x}$-axis).

increase in debris cover was not so pronounced (from 6.2\% to $8.1 \%$ ) and due to the lack of imagery, no information was available on the temporal pattern of change.

During the same period, melt on the glacier tongues exceeded the compensating ice flux which resulted in area reduction. For the glaciers in the Adyl-su basin (mean glacier size: $3.7 \mathrm{~km}^{2}$ ) this resulted in an area loss of $14.9 \%$ for the 35 years between 1971 and 2006. In the Zopkhito basin, the resulting area loss was about $12.6 \%$ for the same time span. The area change of the glaciers in the Zopkhito basin within a similar size class as in the Adylsu basin (these are Zopkhito glacier and Laboda glacier, mean area: $2.58 \mathrm{~km}^{2}$ ) is $13.3 \%$.

In the Alps, changes in glacier area were also observed during similar time periods. In the Ötztal (Austrian Alps), glaciers in the size class of $1-5 \mathrm{~km}^{2}$ lost $11.4 \%$ between 1969 and 1997 and 19.1\% in the period 1969-2007 (Lambrecht and Kuhn, 2007; Abermann et al., 2009). In Switzerland, glaciers in the same size class lost $17.9 \%$ between 1973 and 1999 (Paul et al., 2004). Therefore glaciers with a comparable size lost somewhat less area in the Caucasus compared to the glaciers in the Alps.

\section{Characteristics of sub-debris ice melt}

It is important to note that the study will not determine the total mass balance in the basins, because the existing data basis does not allow such calculations. Instead, the ice melt will be compared for individual elevation bands and thus the general conditions for melt water generation, including the local meteorological situation and the influence of the supra-glacial debris cover are analysed. Based on the field work, subdebris ablation was analysed in detail. In connection with

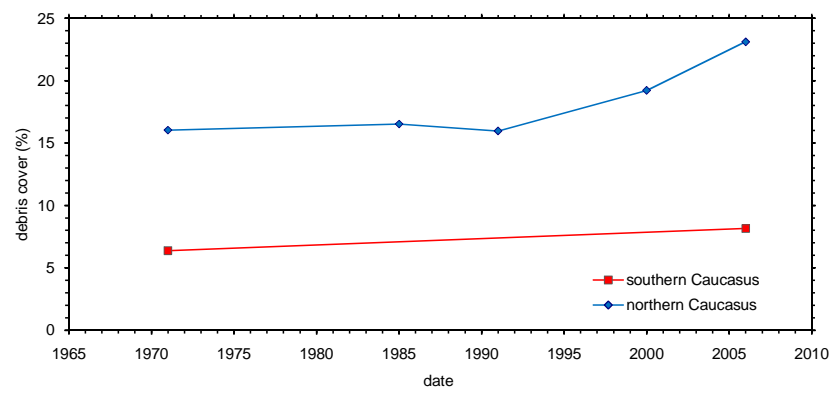

Fig. 8. Relative debris covered area on the glaciers of the two investigated basins in the Caucasus for a time span of 35 years.

mass balance investigations restricted to the ablation zones and meteorological data, glacier melt was calculated for the respective ablation seasons.

As a first step, ablation rates and degree day factors (DDF) were determined as a function of debris thickness for the ablation season. A relationship between daily mean air temperatures and the sub-debris ice melt could be established by assuming the validity of a simple degree day approach (ablation is linearly related to positive air temperatures; Braithwaite 1981, 1995; Hoinkes, 1955; Hoinkes and Steinacker, 1975). A critical investigation of temporal variability of ablation demonstrates that the established degree day relation is not stable over time. Compared to the first week after installation, melt rate is generally higher if longer time spans are considered. The main reason for this is probably considerable mobility of debris cover over time. After installation of a stake in the drill hole of the debris-covered glacier, the debris cover is reassembled as close to natural conditions as possible. This is, however, only possible to a certain extent and leads to a re-organization of the debris layer over time. At the same time, ongoing ice melt changes the ice bed underneath the debris cover leading to the re-structuring of the debris cover. Therefore temporal consolidation and probably also removal of fine grained debris material by melt water at some locations leads to thinning and compaction of the debris cover. Both processes are linked to higher melt rates due to lesser insulation and improved heat conduction. In addition, ablation records at some stakes appear to be spurious. At one location with an initial debris thickness of $12 \mathrm{~cm}$, for example, the degree day factor (melt per degree of positive meain daily air temperature: DD) in 2008 varied from $0.26 \mathrm{~mm} / \mathrm{DD}$ to $0.84 \mathrm{~mm} / \mathrm{DD}$, a value close to the one for clean ice conditions. This is very probably due to a total removal of debris cover by water flow or slumping. Such observations demonstrate that ablation measurements need to be carefully analysed, if they are used for quantifying subdebris melt conditions.

Due to the reasons discussed above, we decided to use only a sub-sample of all measurements which was selected by a quality check of all the ablation measurements. First, the 


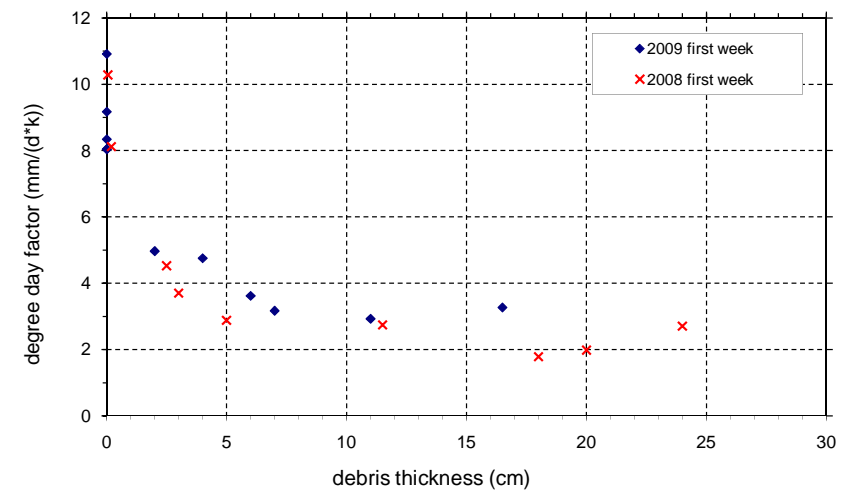

Fig. 9. Degree day factor versus debris thicknesses for the stakes with approved ablation measurements on the Zopkhito Glacier during the observation periods. The maximum ablation is reached for very thin debris layers.

measurements were checked for temporal stability. Frequent observations of ablation especially during the first phase of the measurements in both seasons allowed us to calculate melt rates for short time periods (between half a day and a few days). Only ablation measurements which show stable conditions over several observation periods are selected for further analysis. In addition, photographs of stakes for different dates were checked for stability of the debris cover. The finally selected measurements of ablation and consequently degree day factors as a function of debris thickness are displayed in Fig. 9. The remaining variability of the DDFs is due to local changes in debris cover composition (e.g. grain size, stratigraphy, water content) and is in the order of $1 \mathrm{~mm} / \mathrm{DD}$.

Because the degree day factors as a function of debris thickness are characteristic for specific sites, this relationship is shown in Fig. 10 for several investigated regions. Such a comparison provides information about the effect of debris cover on ice melt in different regions. Even if the extent of glaciation varies between the regions, local ablation rates and thus melt water production can be evaluated. Glacier melt is stronger compared to clear ice melt for a very thin debris cover on both Djankuat and Zopkhito Glaciers. Similar observations were made in other, longer measurements (e.g. Mihalcea et al., 2006; Konovalov, 2000). After a maximum in melt, the melt rate decreases and reaches the same magnitude as for clear ice at the critical debris thickness of about $2 \mathrm{~cm}$ for Zopkhito glacier and $3 \mathrm{~cm}$ for Djankuat glacier. The melt rate continues to decrease rapidly with increasing debris thickness, so that about $50 \%$ of the clear ice value is reached at debris thicknesses of about $6 \mathrm{~cm}$ at Zopkhito glacier and $10 \mathrm{~cm}$ at Djankuat glacier (Fig. 10). This thickness for a $50 \%$ melt reduction is somewhat lower than previously derived values from ablation modelling (Bozhinskiy et al., 1986). In general ice melt is stronger at Djankuat glacier for debris thicknesses between 2 and $13 \mathrm{~cm}$, com-

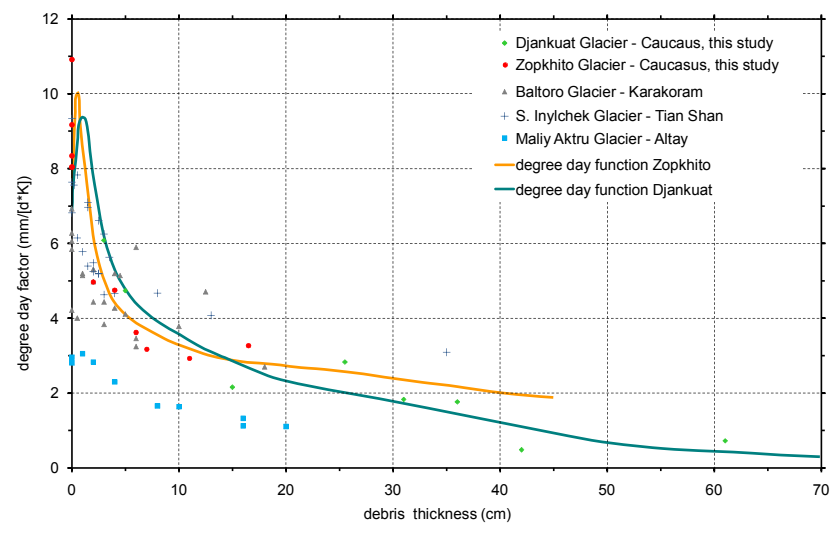

Fig. 10. Degree day factors from different regions (Southern Inylchek, Hagg et al., 2008, Baltoro; Mihalcea et al., 2006; Maliy Aktru, Mayer et al., 2011), including the manually derived degree day functions for Djankuat glacier and Zopkhito glacier.

pared to the conditions at Zopkhito glacier. However, subdebris melt varies considerably depending on the local debris layer conditions (grain size, grain size distribution, humidity, etc). Based on our stake observations, however, the strong reduction of ice melt for debris layer thicknesses between $2 \mathrm{~cm}$ and $10 \mathrm{~cm}$, compared to thicker debris covers seems well documented for both glaciers.

In order to include physical properties of the debris layer in melt calculations, a simple approach based on conduction as the major process of heat transfer from the surface to the ice is used. Furthermore, under the assumption of uniform debris conditions over larger areas (similar grain size distribution, similar lithology, similar water content), heat transfer is governed by thermal resistance. For daily observations, a linear vertical temperature gradient within the debris column can be expected (Nicholson and Benn, 2006) and it can be assumed that energy transferred through the debris cover depends on the temperature gradient $d T / d z$ and its thermal resistance R only (Nakawo and Takahashi, 1982):

$Q_{m}=\frac{1}{R} \frac{d T}{d z}$,

where thermal resistance of the debris cover is defined as a ratio between surface temperature $T_{\mathrm{S}}$ and ablation rate $a$ in dependence of latent heat of fusion $L_{\mathrm{s}}$ and ice density $\rho_{\mathrm{i}}$, if the mean ice surface temperature is assumed to be at the freezing point

$R=\frac{T_{\mathrm{S}}}{L_{\mathrm{S}} \cdot \rho_{\mathrm{i}} \cdot a}$.

From the observed temperature gradients in the debris cover, a mean daily surface temperature can be inferred which is used together with the recorded ablation values at the same position to calculate thermal resistance. As this is done at locations with different debris thicknesses, a function for the thermal resistance in relation to the thickness of the debris 
Table 2. Thermal conductivity for different rock types (Gupta, 2003) and the derived thermal resistance for a $10 \mathrm{~cm}$ thick layer of the respective material.

\begin{tabular}{lcc}
\hline rock & $\begin{array}{c}\text { Thermal } \\
\text { conductivity } \\
\left(\mathrm{W} \mathrm{m}^{-1} \mathrm{~K}^{-1}\right)\end{array}$ & $\begin{array}{c}\text { Thermal resistance } \\
\left(\mathrm{K} \mathrm{m}^{2} \mathrm{~W}^{-1}\right) \\
(\text { for } 10 \mathrm{~cm} \\
\text { debris thickness })\end{array}$ \\
\hline Granite & 3.32 & 0.0301 \\
Basalt & 2.09 & 0.0478 \\
Slate & 2.09 & 0.0478 \\
Limestone & 2.00 & 0.0500 \\
Quartz Sandstone & 5.02 & 0.0199 \\
\hline
\end{tabular}

layer can be deduced. One basic assumption for this approach is a characteristic and constant debris composition across the glacier. Even though the debris composition shows some variability, it is possible to choose measurement locations which are representative of the mean conditions of a certain debris cover thickness.

The accuracy of the thermistors used in the experiments is $\pm 0.2^{\circ} \mathrm{C}$, while daily ablation can be determined with an accuracy of less than $1 \mathrm{~cm}$. Using a mean daily vertical temperature gradient in the debris cover, the resulting mean uncertainty for the derived thermal resistance is \pm 0.02 $\left(\mathrm{K} \mathrm{m}^{2} \mathrm{~W}^{-1}\right)$. This value is in the same order as thermal resistance for very thin debris cover (less than a few $\mathrm{cm}$ ).

Thermal resistance of the debris cover has been calculated as an independent parameter, in order to allow a comparison between different regions. This parameter is independent of the glacier area-elevation distribution and thus general mass balance and topographical conditions. Therefore, local ablation conditions can be compared between different meteorological situations, surface geometry and supra-glacial debris properties.

Thermal resistance is known for different rock types based on their thermal conductivity (Table 2, Gupta, 2003). Thermal resistance of a debris layer, however, is a combination of properties of the rock, the air filling void space and water situated especially in the lower parts of the debris layer (Brock et al., 2007). The thermal resistance of air $\left(3.85 \mathrm{~K} \mathrm{~m}^{2} \mathrm{~W}^{-1}\right.$ for a $10 \mathrm{~cm}$ layer, Young, 1992) is much larger than for typical rock types and water (thermal resistance of a $10 \mathrm{~cm}$ water layer: $0.19 \mathrm{~K} \mathrm{~m}^{2} \mathrm{~W}^{-1}$ ) shows somewhat higher values. Variability of thermal resistance across several regions (Fig. 11) is of the same order as variability between different rocks (Table 2). The considerable difference between Djankuat glacier and other regions is probably due to a different grain size distribution (air content) and water saturation.

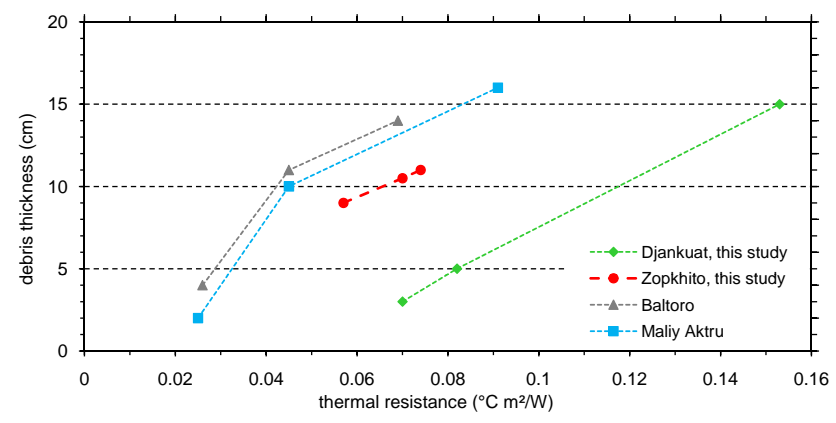

Fig. 11. Thermal resistance for the glaciers in the Caucasus and Altai and compared with results from former field measurements in the Karakoram.

\section{Model simulations of sub-debris ablation}

One of the major goals of this study is to show that a simple approach is suitable for providing reliable estimates of melt water generation in basins with poor data availability. Frequently, daily air temperature is either measured close to glaciers or can be obtained from local meteorological stations in the vicinity. Also precipitation (cumulative values for periods of weeks and months) can be derived from station data in the region. Both air temperature and radiation budget influence the sub-debris ice melt and it would be desirable to use an energy balance model for the calculation of ice melt. In most situations, however, the required input data are not available, especially at high temporal resolution which is required for energy balance models. This is the major motivation for adapting a simple degree day model to determine the cumulated ice melt across the ablation zone of debris covered glaciers with a poor data coverage.

The temporal development of glacier change and the influence of the debris cover can only be described with a combination of an appropriate mass balance model (including the effect of supra-glacial debris) and an associated model of glacier evolution. One of the key components is the treatment of mass loss from the ablation zone and, in the case of debris covered glaciers, the implementation of the sub-debris melt mechanisms. Field measurements can only be carried out on a finite number of sample glaciers and transition from local field results to calculations for larger areas requires the usage of the above mentioned models.

One major issue when discussing variations in glacier water resources is their relevance to the water supply for hydropower or irrigation. Any hydrological model for run-off simulation in glacierized catchments requires input from ablation models for prognostic calculations into the future. A number of hydrological models already exist which include glacier mass balance routines (e.g. HBV-ETH see Braun and Aellen, 1990, or OEZ, see Kuhn and Batlogg, 1998). There is, however, no adequate treatment of debris-covered glaciers in such models. 


\subsection{The ablation model}

In our approach, ablation $a$ is calculated for $50 \mathrm{~m}$ elevation bands, with an appropriate degree day sum $D_{\mathrm{s}}$ for the individual bands. The total glacier area $A$ and the supraglacial debris cover area $A_{\mathrm{d}}$ need to be distributed on the elevation bands together with the mean debris thickness $h$ for a correct melt calculation (Mayer et al., 2011). The required areas are determined from field investigations and glacier mapping using remote sensing. The debris thickness is extrapolated from field measurements, which is only justified for small basins with similar glacier morphology. Finally, ablation is determined on the basis of the glacier maps, debris distribution and the degree day functions:

$a=\frac{\left(A-A_{\mathrm{d}}\right)}{A} D_{\mathrm{s}} d_{\mathrm{f}}(\mathrm{i})+\frac{A_{\mathrm{d}}}{A} D_{\mathrm{s}} d_{\mathrm{d}}(h)$

For clear ice and debris cover ablation, the simple and widely accepted degree day approach (e.g. Braithwaite, 1995) is used because the energy balance terms change strongly across debris covered glaciers and measurements are usually not available in remote basins. The degree day factor for ice $d_{\mathrm{f}}(\mathrm{i})$ and the degree day factors function in dependence off different debris thicknesses $d_{\mathrm{d}}(h)$ are calculated from the field data. The degree day factor function in dependence of debris thickness cannot be derived as a single and at the same time easy to use mathematical function. Therefore, we delineate the function manually as a best fit to the stake measurements (Fig. 10). The comparison of the stake measurements with the corresponding values of the manually derived function shows, however, good correlation. For Zopkhito glacier, the coefficient of determination $\left(r^{2}\right)$ is 0.8 , for Djankuat glacier it is 0.96 . This analysis shows that the modelled degree day functions are suitable to calculate sub-debris melt for the observed range of debris thicknesses.

Information on distribution of debris thickness with altitude is required for this calculation. A wide range of observations on different glaciers shows that in general debris thickness increases with decreasing altitude. For individual glaciers, a mean debris thickness function with elevation can be derived and included in the calculations. The summation of the resulting mean ablation rate for the individual elevation bands gives the total ablation for the entire ablation zone. The debris cover thickness for the glaciers in the region was extrapolated from the local thickness measurements, assuming similar thickness/elevation distributions on the neighbouring glaciers. As geological and hypsometric conditions are similar at individual glaciers in the respective basins, this assumption is justified. For larger basins, the relation between debris thickness and elevation needs to be determined for smaller, consistent units. The spatial debris cover distribution for all glaciers is based on classification of optical remote sensing images. The debris thickness is then assigned to mapped debris cover according to the corresponding elevation difference from the glacier snout as on the
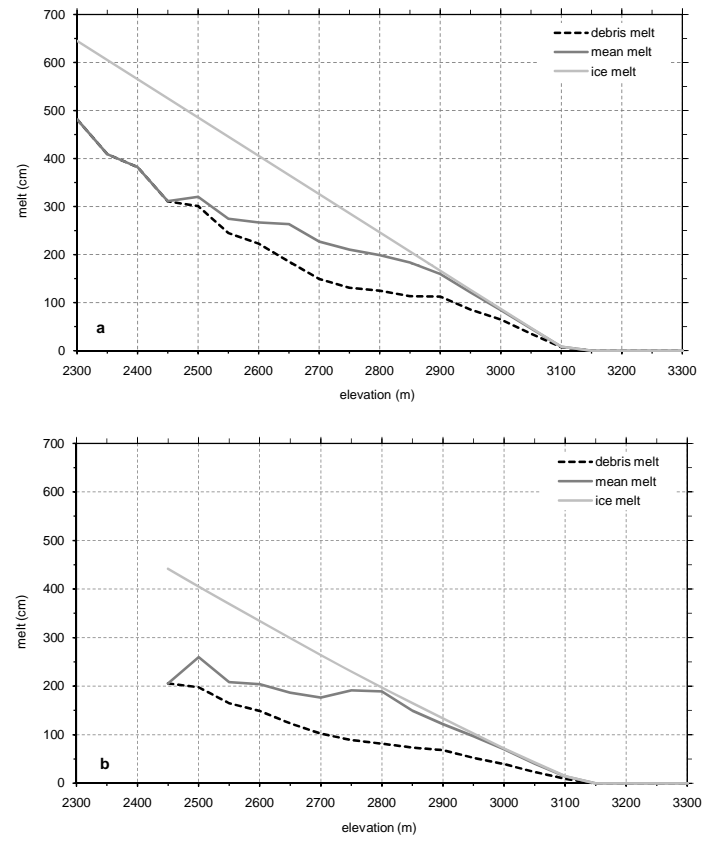

Fig. 12. Model results of net ablation for the two glacier basins and the sample year 2008. (a) Northern test basin (b) Southern test basin, based on a degree day approach and including the effect of supra-glacial debris. For the sub-debris melt, the specific conditions documented by our field measurements are used for the entire basin. Temperature information is provided by the glacier AWS on the Djankuat Glacier and a weather station at Ambrolauri in Georgia for the Zopkhito basin respectively.

glaciers with measured debris thicknesses. For the glaciers in the Adyl-su basin, the thickness measurements on Djankuat Glacier from 2008 could be complemented by detailed debris mapping on this glacier in earlier years (Popovnin and Rozova, 2002). In the Zopkhito basin, the measurements of 2008 and 2009 have been the only ground truth source.

In our experiments, the winter snow pack is assumed to be evenly distributed over the ablation area and is melted first using a mean degree day factor for snow $(0.54 \mathrm{~cm} / \mathrm{DD}$, mean value for similar conditions in Hock, 2003). The amount of snow on the glacier at the end of the winter is derived from precipitation temperature records, which allow discrimination between liquid and solid precipitation. As we are only interested in the effect of the debris cover on the ice ablation, mean values for the end of the winter snow pack are used for calculating snow melt and the start of ice ablation. Summer snow events are very rare on the glacier tongues in both regions and are thus not included in the model experiments.

\subsection{Model results}

Based on this melt model, the net ablation during one sample year (2008) was calculated for the two regions north and south of the Main Ridge. The results are shown in Fig. 12. 
Table 3. Results from sensitivity experiments of the ablation model for the Adyl-su basin. In experiment 1 the natural debris thickness distribution is varied across the glacier. For experiment 2 the natural debris cover is used, but the thickness is set to constant values. In experiment 3 the winter snow cover is changed by $\pm 20 \%$. In addition to the resulting melt volume also the relation to the ablation for a debris free glacier is presented.

\begin{tabular}{|c|c|c|c|c|c|}
\hline experiment 1 & & & & & \\
\hline & real debris & real $-10 \%$ & real $+10 \%$ & real $+20 \%$ & \\
\hline total melt volume $\left(\mathrm{m}^{3}\right)$ & 2773602 & 2810788 & 2763769 & 2738032 & \\
\hline clean glacier ratio $(\%)$ & 73.7 & 74.7 & 73.4 & 72.7 & \\
\hline \multicolumn{6}{|l|}{ experiment 2} \\
\hline & real debris & $2 \mathrm{~cm}$ debris & $5 \mathrm{~cm}$ debris & $10 \mathrm{~cm}$ debris & $15 \mathrm{~cm}$ debris \\
\hline total melt volume $\left(\mathrm{m}^{3}\right)$ & 2773602 & 3348247 & 2909847 & 2734487 & 2646808 \\
\hline clean glacier ratio ( $\%$ ) & 73.7 & 88.9 & 77.3 & 72.6 & 70.3 \\
\hline \multicolumn{6}{|l|}{ experiment 3} \\
\hline & initial snow & initial $-20 \%$ & initial $+20 \%$ & & \\
\hline total melt volume $\left(\mathrm{m}^{3}\right)$ & 2773602 & 4265021 & 1847831 & & \\
\hline clean glacier ratio $(\%)$ & 73.7 & 77.9 & 70.4 & & \\
\hline
\end{tabular}

Table 4. Results from sensitivity experiments of the ablation model for the Zopkhito basin. The experiments are identical to the ones in Table 3.

\begin{tabular}{|c|c|c|c|c|c|}
\hline \multicolumn{6}{|l|}{ experiment 1} \\
\hline & real debris & real $-10 \%$ & real $+10 \%$ & real $+20 \%$ & \\
\hline total melt volume $\left(\mathrm{m}^{3}\right)$ & 17876838 & 1604183 & 17771961 & 17323313 & \\
\hline clean glacier ratio (\%) & 73.7 & 76.7 & 73.2 & 71.4 & \\
\hline \multicolumn{6}{|l|}{ experiment 2} \\
\hline & real debris & $2 \mathrm{~cm}$ debris & $5 \mathrm{~cm}$ debris & $10 \mathrm{~cm}$ debris & $15 \mathrm{~cm}$ debris \\
\hline total melt volume $\left(\mathrm{m}^{3}\right)$ & 17876838 & 25743291 & 19417301 & 16886905 & 15305407 \\
\hline clean glacier ratio $(\%)$ & 73.7 & 106.1 & 80.0 & 69.6 & 63.1 \\
\hline \multicolumn{6}{|l|}{ experiment 3} \\
\hline & initial snow & initial $-20 \%$ & initial $+20 \%$ & & \\
\hline total melt volume $\left(\mathrm{m}^{3}\right)$ & 17876838 & 29605310 & 9882082 & & \\
\hline clean glacier ratio (\%) & 73.7 & 77.7 & 69.5 & & \\
\hline
\end{tabular}

For both regions, the calculated equilibrium line altitude (ELA) is in the same range, but lower in the south (about $3100 \mathrm{~m}$ in the Zopkhito basin) than in the north $(3300 \mathrm{~m}$ in the Adyl-su basin). The clean ice ablation, however, shows a larger gradient in the north. One possible reason could be the observed higher cloudiness on the southern slope of the Caucasus which results in smaller values of the incoming short wave radiation and, therefore, lower air temperature under otherwise similar meteorological conditions. Another reason could be the different aspect of the glaciers, where the southfacing glaciers receive more energy but also more precipitation. This radiation conditions, however, do not result in a lower position of the glacier terminus. This effect is probably linked to the mean orientation of the glaciers (north-west in the north and south-east/south/south-west in the south) and a difference in the precipitation regime with large accumulation amounts on the northern slopes of the Caucasus (Popovnin, 1999). Compared to the northern glaciers, the lower limit of the glaciers in the Zopkhito region is about $150 \mathrm{~m}$ higher, while the total clear ice ablation at $2450 \mathrm{~m}$ elevation is $120 \mathrm{~cm}$ or $20 \%$ less for the sample year.

In both regions, debris cover strongly influences total melt. The ablation-elevation function is determined by debris distribution and thickness. For both examples, the effect of the debris cover declines strongly above about $2850 \mathrm{~m}$ due to very little debris cover at higher elevations. In total, ice melt is reduced by about $26 \%$ due to the debris cover in both basins. However, distribution of melt characteristics with 
altitude is rather different, with a more gradual decrease of debris cover in the northern basin.

For both regions the total amount of melt water was determined for the ablation season 2008 , resulting in $2.77 \times 10^{6} \mathrm{~m}^{3}$ for the Zopkhito basin and $17.88 \times 10^{6} \mathrm{~m}^{3}$ for the Adyl-su basin. This corresponds to additional $56 \mathrm{~mm}$ discharge in the Zopkhito basin and $180 \mathrm{~mm}$ in the Adyl-su basin. Unfortunately mass balance measurements are only available for Djankuat glacier. Therefore, a direct comparison is only possible for this glacier. In the mass balance year 2007/08, Djankuat glacier had a positive mass balance of $100 \mathrm{~mm}$. The mean ice melt across the ablation area was $2470 \mathrm{~mm}$ which was more than compensated by the large accumulation amounts. If the mean ablation of the model result for 2008 is scaled with the ablation area of Djankuat glacier, the ice melt results in $2580 \mathrm{~mm}$, which is in a good agreement with the measurements. In the case of a debris-free glacier, ice melt would be enhanced by $26.3 \%$, resulting in a mean ice melt of $3345 \mathrm{~mm}$ in the ablation area and an estimated mass balance of $-290 \mathrm{~mm}$. This compares well to results by Pelto (2000), who identified that annual ablation was significantly reduced by $25-30 \%$ on debris-covered ice, with summer ablation (once all snow cover has been lost) $30-40 \%$ less under debris-covered regions.

In order to assess the significance of these results, additional experiments have been performed with different parameter sets (Tables 3 and 4). Compared to the results for the actual debris cover thickness, a thickness change of $10 \%$ results in rather small variations (up to $1 \%$ ) of the effect of the debris cover on ice melt for the Zopkhito basin. A $10 \%$ increase of the debris cover thickness reduces the ice melt by about $10000 \mathrm{~m}^{3}$, or $0.35 \%$, while a corresponding thickness decrease enhances ice melt by $37000 \mathrm{~m}^{3}$, or $1.3 \%$. In the Adyl-su basin, the effect of thickness change is higher. If the debris cover thickness is reduced, the influence of the debris cover on ice melt increases by $3 \%$. The melt water production is $1.8 \times 10^{6} \mathrm{~m}^{3}$, or $10 \%$ higher. For an increase of the debris thickness of $10 \%$, the reduction of melt water production is $105000 \mathrm{~m}^{3}$, or $0.6 \%$. This strong difference in sensitivity is due to the fact that the mean debris thickness of about $8 \mathrm{~cm}$ in the Adyl-su basin is close to the strong slope of the derived degree day function (Fig. 10), resulting in strong changes for small debris thickness changes. For a similar mean debris thickness in the Zopkhito basin the corresponding degree day function is already rather flat and ablation is less sensitive to thickness changes. This is also confirmed by experiments with constant debris thicknesses across the glaciers. The variation of the debris cover thickness between $5 \mathrm{~cm}$ and $15 \mathrm{~cm}$ for the Zopkhito basin produces only moderate changes in the total melt water production, while the variation between $5 \mathrm{~cm}$ and $2 \mathrm{~cm}$ increases the ice melt considerably more. In the Adyl-su basin, the corresponding experiments show that the melt water production for a mean debris thickness of $2 \mathrm{~cm}$ is higher than for clear glaciers (106\%), while changes in debris thickness between $10 \mathrm{~cm}$ and $15 \mathrm{~cm}$ show only a minor effect. These differences in ice melt sensitivity to debris thickness variations can be explained by the observed debris thickness distribution in the basins and the characteristic degree day functions for the two basins.

A variation in winter accumulation $( \pm 20 \%)$ has a strong effect on the total melt water production, but the effect on the role of the debris cover for ice melt is restricted (about $4 \%$ ).

\section{Discussion and conclusions}

This study compares the conditions of glacier melt on both sides of the main divide of the Caucasus Range. In both regions, debris cover has a moderate effect on the melt water production. The altitudes below $2800 \mathrm{~m}$ a.s.l. are affected by an increasing debris cover in thickness and in areal extent. This trend will continue if the climate evolves along the current trends due to continuous strong ice melt and accumulation of supra-glacial debris on the glacier tongues. Therefore any investigation of glacier melt in this region needs to take debris cover into account.

A comparison of derived degree day factors as a function of supraglacial debris thickness for different glaciated regions (Fig. 10) shows that the measurements in the Caucasus provide factors in a similar range as in the Karakoram (Mihalcea et al., 2006) and the Tian Shan (Hagg et al., 2008). For thin debris layers, however, the variation of the factors is large and between the regions, melt rates can vary by a factor three. This is mainly due to geographical conditions (latitude, elevation), local geology (defining debris surface albedo and thermal resistance) and meteorological conditions (cloudiness). In the Caucasus, the relation between degree day factors and debris thickness is similar in the northern and the southern parts as documented by our investigations.

Ice ablation will be smaller at the Djankuat Glacier in the Caucasus for a given debris surface temperature, compared to similar ablation values at the Baltoro Glacier and the Maliy Aktru Glaciers (Fig. 11). For the Zopkhito Glacier, thermal resistance is smaller than for the Djankuat Glacier and just slightly higher than for the Baltoro and Maliy Aktru Glaciers. Given the mean uncertainty of thermal resistance of 0.02 $\left(\mathrm{K} \mathrm{m}^{2} \mathrm{~W}^{-1}\right)$, the results for Zopkhito glacier are significantly different from those for Djankuat glacier. This difference in thermal resistance is probably due to different geological conditions in the two basins. Melting is thus enhanced on the Zopkhito Glacier in comparison to its northern counterpart for the same boundary conditions and glaciers in the Adyl-su basin are less sensitive to changes in the debris cover.

On the other hand, the degree day factors in dependence of debris thickness for Djankuat and Baltoro glaciers (Fig. 10) are rather similar. This is probably due to the large altitude and thus mean air temperature difference between the two glaciers which, to a certain extent, compensates the physical property differences of the debris cover. The observations 
also show that within this comparison melt is most effective on the Southern Inylchek Glacier in the Tian Shan. This might be due to regular rainfall in this region, which provides a very effective energy transport by advection in addition to conduction, especially through small debris thicknesses.

Our analysis indicates also that the debris cover increases more rapidly in the north than in the south. Due to the climatic and topographic conditions, the investigated glaciers south of the divide have almost the same size compared to their northern counterparts, although smaller glaciers exist as well in high cirques. The southern aspect allows higher radiation input and thus more intensive ice melt, which is more than compensated by the general cloud distribution. On the other hand, higher cloudiness results in higher precipitation in the south than in the north. This is reflected in the modeling results, which show that for the same time period the effective glacier melt is about $20 \%$ less in the south.

Both regions experienced a strong glacier area loss during the last decades and the gradual increase in debris cover only has a moderating effect on the lower $300 \mathrm{~m}-400 \mathrm{~m}$ of the glacier tongues. There the mass loss is reduced by 20-30\% which slows down the retreat rates of the glaciers and lowers the total discharge by about a quarter. Moderate thickness changes of the debris cover, as can be expected for the near future, have only a small influence on the resulting melt volume. This indicates that the effect of the debris cover on the total melt water production is rather stable and will gradually change with an increasing supra-glacial debris cover.

Acknowledgements. We gratefully acknowledge the financial support by the EU-INTAS project "Modelling Climate Change, Glacier Dynamics, and Water Availability in the Caucasus", and the "EGREW" project of the Austrian Academy of Sciences. Research on the Djankuat Glacier was also funded by project 3271.2010.5 of Federal Program "Leading Scientific Schools of Russia" and grant No. 09-05-01182a of Russian Foundation of Basic Research. We thank all our Georgian and Russian colleagues for their valuable help during the time at the glaciers. M. Shahgedanova strongly improved the manuscript by correcting the language and identifying inconsistencies. Two anonymous reviewers provided useful suggestions and comments which clearly enhanced the quality of the paper.

Edited by: J. O. Hagen

\section{References}

Abermann, J., Lambrecht, A., Fischer, A., and Kuhn, M.: Quantifying changes and trends in glacier area and volume in the Austrian Ötztal Alps (1969-1997-2006), The Cryosphere, 3, 205215, doi:10.5194/tc-3-205-2009, 2009.

Bozhinskiy, A. N., Krass, M. S., and Popovnin, V. V.: Role of debris cover in the thermal physics of glaciers, J. Glaciol., 32(111), 255-266, 1986.

Braithwaite, R. J.: On glacier energy balance, ablation and air temperature, J. Glaciol., 27(97), 381-391, 1981.
Braithwaite, R. J.: Positive degree-day factors for ablation on the Greenland ice sheet studied by energy-balance modelling, J. Glaciol., 41(137), 153-160, 1995.

Braun, L. N. and Aellen, M.: Modelling discharge of glacierized basins assisted by direct measurements of glacier mass balance, in Hydrology in Mountainous Regions, IAHS Publ., 193, 99-106, 1990.

Brock, B. Rivera, A., Casassa, G., Bown, F., and Acuna, C.: The surface energy balance of an active ice-covered volcano: Villarrica Volcano, Southern Chile, Ann. Glaciol., 45, 104-114, 2007.

Dolgushin, L. D. and Osipova, G. B.: Glaciers, Moscow, Misl Publishing, 447, 1989, (in Russian).

Foster, L. A.: Utilisation of remote sensing for the study of debriscovered glaciers: development and testing of techniques on Miage Glacier, Italian Alps, School of Social and Environmental Science, University of Dundee, Theses, 272 pp, 2010.

Fujii, Y.: Experiment on glacier ablation under a layer of debris cover, J. Japan. Soc. Snow fee (Seppyo), 39, 20-21, 1977.

Geologia SSSR (USSR Geology), Vol. IX "Northern Caucasus", 1968, and Vol. X "Georgian SSR”, 1964.

Gupta, R. P.: Remote Sensing Geology, Springer, New York, 656 pp, 2003.

Hagg, W., Mayer, C., Lambrecht, A., and Helm, A.: Sub-debris melt on Southern Inylchek glacier, central Tien Shan, Geogr. Ann., 90, 55-63, 2008.

Hock, R.: Temperature index melt modelling in mountain areas, J. Hydrol., 282, 104-115, 2003.

Hoinkes, H. C.: Measurements of ablation and heat balance on Alpine glaciers, J. Glaciol., 2(17), 497-501, 1955.

Hoinkes, H. C. and Steinacker, R.: Zur Parametrisierung der Beziehung Klima-Gletscher, Rivista Italiana di Geofisica e Scienze Affini, Vol. I (Speciale), 97-104, 1975.

Kayastha, R. B., Takeuchi, Y., Nakawo, M., and Ageta, Y.: Practical prediction of ice melting beneath various thickness of debris cover on Khumbu Glacier, Nepal, using a positive degree-day factor, IAHS Publ., 264, 71-81, 2000.

Konovalov, V.: Computations of melting under moraine as a part of a regional modelling of glacier runoff, IAHS Publ., 264, 109118, 2000.

Kuhn, M. and Batlogg, N.: Glacier runoff in Alpine headwaters in a changing climate, IAHS Publ., 248, 79-88. 1998.

Lambrecht, A. and Kuhn, M.: Glacier changes in the Austrian Alps during the last three decades, derived from the new Austrian glacier inventory, Ann. Glaciol., 46, 177-184, 2007

Mattson, L. E., Gardner, J. S., and Young, G. J.: Ablation on devris covered glaciers: an example from the Rakhiot Glacier, Panjab, Himalaya, IAHS Publ., 218, 289-296, 1993.

Mayer, C., Lambrecht, A., Mihalcea, C., Beló, M., Diolaiuti, G., Smiraglia, C., and Bashir, F.: Analysis of Glacial Meltwater in Bagrot Valley, Karakoram Based on Short-term Ablation and Debris Cover Observations on Hinarche Glacier, Mt. Res. Dev., 30(2), 169-177, 2010.

Mayer, C., Lambrecht, A., Hagg, W., and Narozhny, Y.: Glacial debris cover and melt water production for glaciers in the Altay, Russia, The Cryosphere Discuss., 5, 401-430, doi:10.5194/tcd5-401-2011, 2011.

Mihalcea, C., Mayer, C., Diolaiuti, G., Smiraglia, C., and Tartari, G.: Ablation conditions on the debris covered part of Baltoro Glacier, Karakoram, Ann. Glaciol., 43, 292-300, 2006. 
Mihalcea, C., Brock, B. W., Diolaiuti, G., D'Agata, C., Citterio, M., Kirkbride, M. P., Cutler, M. E. J., and Smiraglia, C.: Using ASTER satellite and ground-based surface temperature measurements to derive supraglacial debris cover and thickness patterns on Miage Glacier (Mont Blanc Massif, Italy), Cold Reg. Sci. Technology, 52(3), 341-354, doi:10.1016/j.coldregions.2007.03.004, 2008a.

Mihalcea, C., Mayer, C., Diolaiuti, G., D’Agata, C., Smiraglia, C., Lambrecht, A., Vuillermoz, E., and Tartari, G.: Spatial distribution of debris thickness and melting from remote-sensing and meteorological data, at debris-covered Baltoro glacier, Pakistan, Ann. Glaciol., 48, 49-57, 2008b.

Nakawo, M. and Young, G.: Field Experiments to determine the Effect of a Debris Layer on ablation of Glacier Ice, Ann. Glaciol., 2, 85-91, 1981.

Nakawo, M., and Takahashi, S.: A simplified model for estimating glacier ablation under a debris layer, IAHS Publ. 138, 137-145, 1982.

Nicholson, L. D. and Benn, I.: Calculating ice melt beneath a debris layer using meteorological data, J. Glaciol., 52(178), 463-470, 2006.

Østrem, G. : Ice melting under a thin layer of moraine, and the existence of ice cores in moraine ridges. Geogr. Ann., 41(4), 228230, 1959.

Paul, F., Kääb, A., Maisch, M., Kellenberger, T. W., and Haeberli, W.: Rapid disintegration of Alpine glaciers observed with satellite data, Geophys. Res. Lett., 31, L21402, doi:10.1029/2004GL020816, 2004.

Pelto, M.: Mass balance of adjacent debris-covered and clean glacier ice in the North Cascades, Washington, IAHS Publ., 264, 35-42, 2000.

Popovnin, V. V.: Annual mass-balance series of a temperate glacier in the Caucasus, reconstructed from an ice core, Geografiska Annaler, Series A, 81(4), 713-724, 1999.

Popovnin, V. V. and Rozova, A. V.: Influence of sub-debris thawing on ablation and runoff of the Djankuat Glacier in the Caucasus, Nord. Hydrol., 33(1), 75-94, 2002.

Rabus, B., Eineder, M., Roth, A., and Bamler, R.: The shuttle radar topography mission - a new class of digital elevation models acquired by spaceborne radar, ISPRS J. Photogr. Remote Sens., 57(4), 241-262, 2003.

Reid, T. and Brock, B. W.: An energy-balance model for debris-covered glaciers including heat conduction through the debris layer, J. Glaciol., 56(199), 903-916, doi:10.3189/002214310794457218, 2010.
Scherler, D., Bookhagen, B. and Strecker, M. R.: Spatially variable response of Himalayan glaciers to climate change affected by debris cover, Nat. Geosci., 4, 156-159, doi:10.1038/ngeo1068, 2011.

Shahgedanova, M., Hagg, W., Hassell, D., Stokes, C. R., and Popovnin, V.: Climate Change, Glacier Retreat, and Water Availability in the Caucasus Region, in: Threats to Global Water Security, edited by: Jones, J. A. A., Vardanian, T., and Hakopian, C., Proceedings of the NATO Advanced Research Workshop on Natural Disasters and Water Security: Risk Assessment, Emergency Response and Environmental Management, 13-18 October 2007, Armenia, Yerevan, 131-143, 2009a.

Shahgedanova, M., Hagg, W., Zacio, M., and Popovnin, V.: An Assessment of the Recent Past and Future Climate Change, Glacier Retreat, and Runoff in the Caucasus Region Using Dynamical and Statistical Downscaling and HBV-ETH Hydrological Model, in: Regional Aspects of Climate-terrestrial-Hydrologic Interactions in Non-boreal Eastern Europe, edited by: Groisman, P. Ya. and Ivanov, S., Springer Science and Business Media B.V., 6372, 2009b.

Stokes, C. R., Gurney, S. D., Shahgedanova, M., and Popovnin, V.: Late-20th-century changes in glacier extent in the Caucasus Mountains, Russia/Georgia, J. Glaciol., 52(176), 99-109, 2006.

Stokes, C. R., Popovnin, V., Aleynikov, A., and Shahgedanova, M.: Recent glacier retreat in the Caucasus Mountains, Russia, and associated changes in supraglacial debris cover and supra/proglacial lake development, Ann. Glaciol., 46, 196-203, 2007.

Taschner, S. and Ranzi, R.: Comparing the Opportunities of LANSAT-TM and ASTER Data for Monitoring a Debris Covered Glacier in the Italian Alps within GLIMS Project, International Geoscience and Remote Sensing Symposium (IGARSS), 2, 1044-1046, 2002.

Takeuchi, Y., K. R. B. and Nakawo, M.: Characteristics of ablation and heat balance in debris-free and debris-covered areas on Khumbu Glacier, Nepal Himalayas, IAHS Publ., 264, 53-61, 2000.

Volodicheva, N. A.: The Caucasus, in: The Physical Geography of Northern Eurasia, edited by: Shahgedanova, M., Oxford University Press, 284-313, 2002.

WGMS: Glacier mass balance bulletin No. 10 (2006-2007), edited by: Haeberli, W., Gärtner-Roer, I., Hoelzle, M., Paul, F., and Zemp, M., ICSU(WDS)/IUGG(IACS)/UNEP/UNESCO/WMO, World Glacier Monitoring Service, Zürich, 96 pp., 2002.

Young, Hugh D.: University Physics, 7 Edn., Addison Wesley, 1992. 